\title{
Designing the Siilinjärvi thickened tailings storage facility
}

\author{
TG Fitton Fitton Tailings Consultants, Australia
}

B Henriksson Outotec Oyj, Finland

E Ruhanen Yara Siilinjärvi, Finland

\begin{abstract}
This case study presents some of the key aspects of the design of the thickened tailings storage facility that recently commenced operation at Yara's Siilinjärvi apatite mine in Finland. The mine is located near the Arctic Circle, and therefore operates in a cold climate. The tailings are also quite coarse (with a $D_{90}$ of 700 microns), which creates challenges in the operation of a thickened tailings storage facility. This paper describes a series of pilot plant trials from 2007 to 2010 and demonstration plant beaching trials that took place in 2013 and 2014, not only in terms of the collection of data, but also with respect to the many engineering challenges that were overcome in the thickening and transport of the tailings slurry under these difficult conditions. The beaching trials provided good validating data for the design of the tailings storage facility. The beaching results are presented, along with some discussion of their comparison with the predicted beach slopes used in the tailings storage facility design. The paper further discusses and presents images of the thickeners, pumps, pipelines and tailings storage area.
\end{abstract}

Keywords: thickened tailings, beach slope, cold climate, tailings storage facility

\section{Introduction}

The Siilinjärvi apatite mine in Finland has been operating for about 38 years. Apatite is a mineral that is a rich source of phosphate. The current owner of the mine, Yara International ASA, is a Norwegian chemical company. Yara's largest business area is the production of nitrogen fertiliser. The Yara Siilinjärvi complex in the Eastern Province of Finland consists of the mine, two sulphuric acid plants, one phosphoric acid plant, one nitric acid plant and one nitrogen-phosphorus-potassium (NPK) fertiliser plant. The Siilinjärvi complex currently employs about 800 people in the local area. Annually the mine produces about one million tonnes of apatite concentrate, and about ten million tons of tailings.

For the past 15 years, tailings from the mine have been discharged into the Musti tailings storage. This is a conventional tailings impoundment situated against a hillside, with earthfill dams forming the storage boundary along much of the impoundment perimeter. There are also upstream raised embankments being constructed on the tailings surface for increasing storage capacity. The Musti tailings storage area is about $4.5 \mathrm{~km}$ long and about $2.5 \mathrm{~km}$ wide. The perimeter dams have been raised several times during the life of the Musti storage, with each raise being constructed by downstream methods. Whilst this approach is generally safer (and thus preferable) to the alternatives, each raise becomes progressively more expensive than the last, and the footprint of the dam expands further into the area surrounding the storage. The most significant problem was that the Musti tailings storage facility (TSF) was approaching its ultimate capacity, as there was no more space available downstream for additional dam raises, and there were no other suitable sites available for developing a new tailings storage facility.

The Siilinjärvi tailings is quite unusual in comparison to tailings from other mines, because about $65 \%$ of the solids (by weight) consist of mica flakes. The tailings is also quite coarse, with a $D_{90}$ of about 700 microns, so it very rapidly settles. 


\section{Thickened tailings storage}

Yara was aware of the potential for achieving steeper beach slopes with a thickened tailings storage facility, and the possible exploitation of this technology to accommodate more tailings at a greater depth on the same footprint. Eli Robinsky, the inventor of the central thickened discharge (CTD) type TSF, had visited the Siilinjärvi mine in 1981, and had carried out a feasibility study for a CTD to be developed on the site. At the time, it was concluded that the thickening technology available would not be capable of producing a sufficiently high concentration of slurry to satisfy Robinsky's conceptual design. One of the major challenges of operating a thickener at the site was the rapidly settling coarse particles.

Some 20 years after the mine's establishment, the tailings storage at the mine was configured with an elevated discharge point. Even though the thickener was producing an underflow concentration of only $45 \%$ $(\mathrm{w} / \mathrm{w})$ at the time, it was found that the tailings was beaching at slopes exceeding $3 \%$. This effectively resulted in a conical shaped tailings deposit like a CTD, despite the tailings only being moderately thickened.

\section{$3 \quad$ Pilot testing for a thickened tailings storage facility}

Thickening technology has made some major progress during the past 20 years, and Yara sought to explore options for achieving steeper beach slopes to increase the life of the tailings storage facility. In 2006, Outotec was engaged to carry out a campaign of laboratory-scale testwork. Laboratory and one metre pilot scale testwork continued through 2007-2010 on total tails and cyclone overflow samples. Results on the total tailings stream consistently showed underflow density between 67 and $74 \%$ solids could be achieved with resultant unsheared vane yield stress ranging from $200-400 \mathrm{~Pa}$. The material was, however, very shear-sensitive with even minor agitation causing a large reduction in yield stress and segregation of coarse and fine fractions in the slurry.

A $1 \mathrm{~m}$ diameter pilot scale thickener was set up at the mine site in 2010 (Figure 1), and testing was performed with the all-in tailings stream, as well as on cycloned tailings streams.

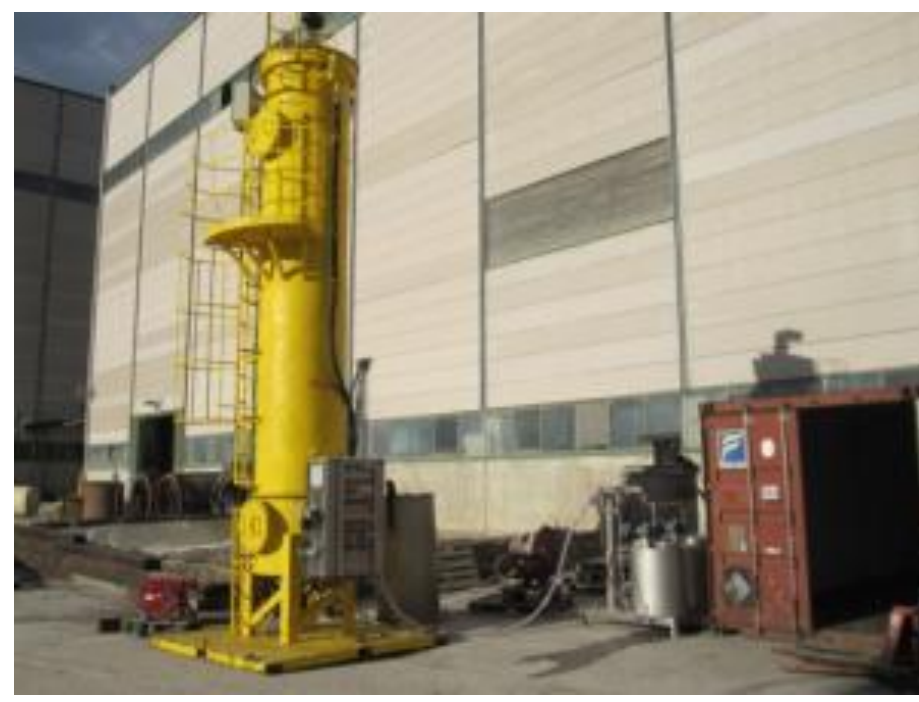

(a)

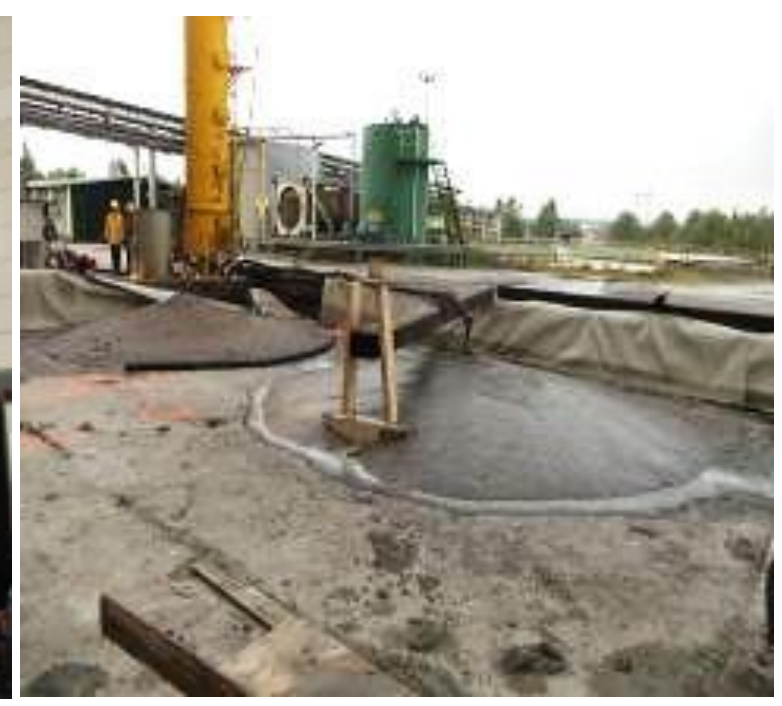

(b)

Figure 1 (a) One metre diameter pilot scale thickener; and, (b) Small tailings deposits created with it

Whilst the laboratory and pilot scale testing provided useful information for the thickening potential, pumping conditions replicating full-scale operation at high density were not achieved, and therefore deposition testing of the tailings also yielded results of limited value for scale-up. 


\section{Demonstration plant}

To better understand the thickening, pumping and deposition characteristics of the slurry, Yara commissioned Outotec to build a demonstration plant with a 14 metre thickener in 2012 (Figure 2). The plant was operated in a series of operational trials until 2014, processing both the all-in tailings slurry and cyclone overflow. The plant was designed to treat up to $100 \mathrm{t} / \mathrm{hr}$ (approximately $10 \%$ of the total tailings from the Siilinjärvi operation).

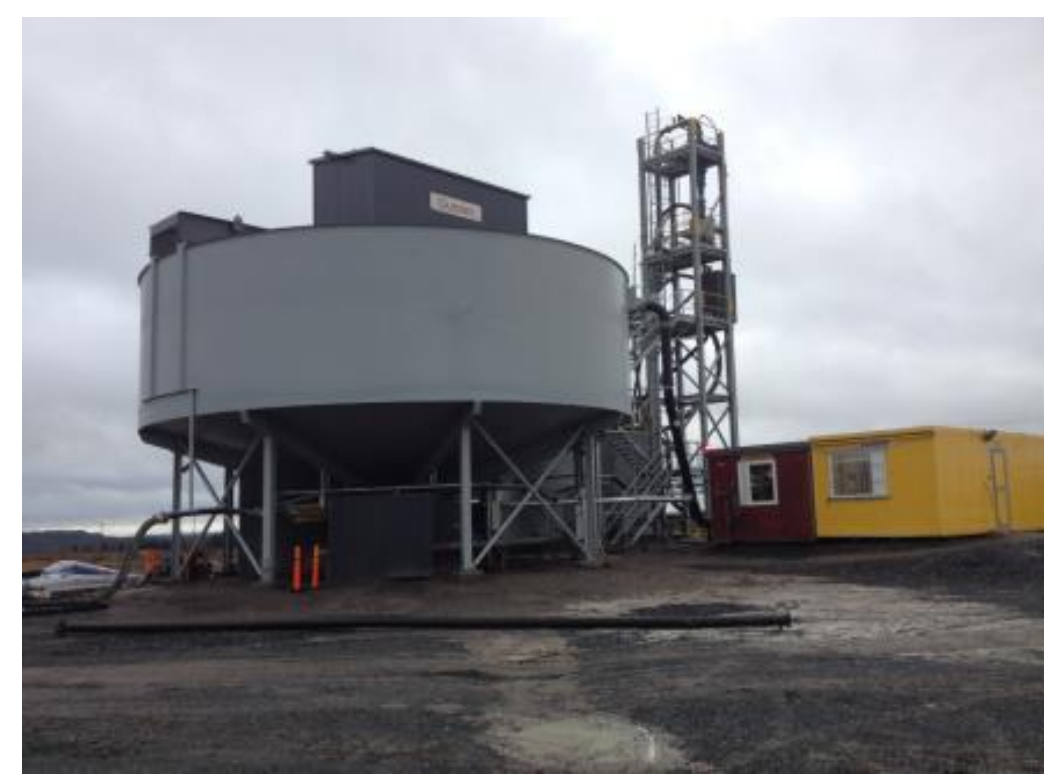

Figure 2 Fourteen metre diameter high-compression thickener that was operated during 2013 and 2014

The high settling rate of the coarse solids in the total tails material presented challenging conditions for the operation of the thickener, as it was found to quickly form a dense bed that presented very high resistance to the rakes. As a result, initial performance from the thickener was highly variable, and although the target density of between 68 and $70 \%$ solids was achieved, periods of density variation and rake torque problems dominated the results. Modification of the thickener was undertaken in several stages between campaigns, with the aim of achieving greater operational consistency. Of most significance was an increase in rake drive torque, static picket installation to prevent bed rotation, and a floor slope increase to $40^{\circ}$.

In 2014, design of the thickener was such that stable operation was achieved on the total tails. Figure 3 shows the underflow concentration produced by the thickener over a period of several days at solids loading rates of $1.3 \mathrm{t} / \mathrm{m}^{2}$.hr decreasing to $0.95 \mathrm{t} / \mathrm{m}^{2}$.hr. Consistent operation between 68 and $70 \%$ solids $(\mathrm{w} / \mathrm{w})$ was demonstrated over this period, which reflected typical performance following the modifications.

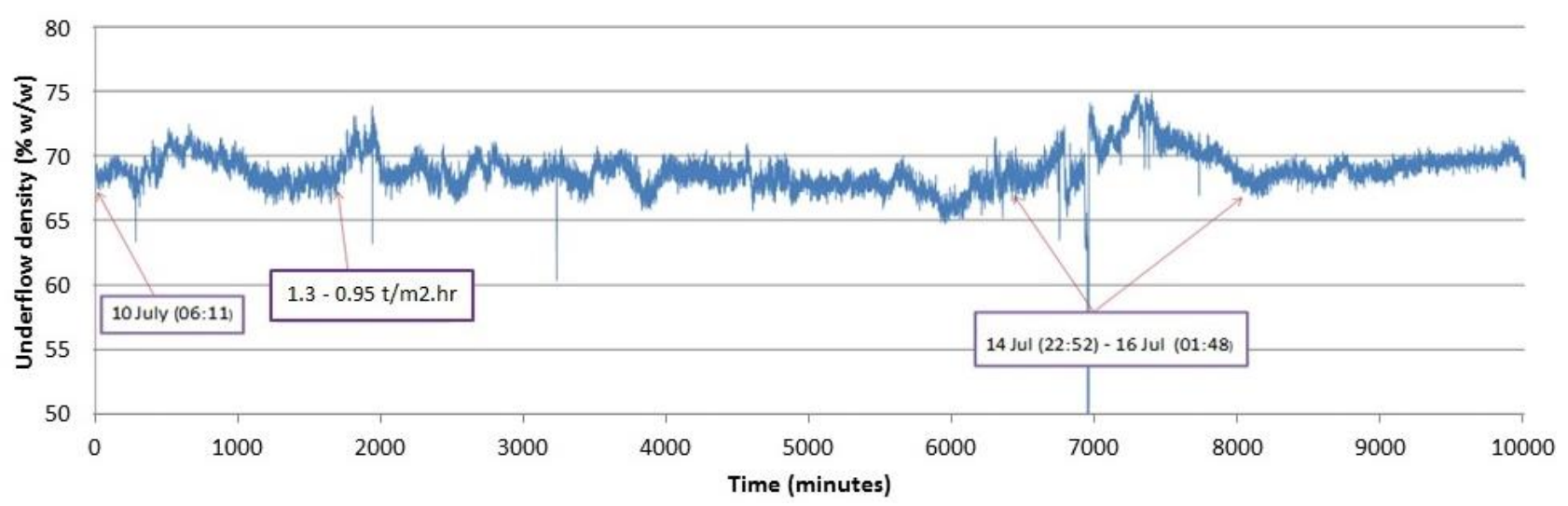

Figure 3 Plot showing the thickener underflow concentration over an eight day period in 2014 
The cold operating conditions during winter (around $-30^{\circ} \mathrm{C}$ ) also created several challenges for the operation of the pilot plant, all of which had to be overcome. These included freezing of the slurry in the feed line and underflow line, both of which had to be coated with heat traces and insulation. There was also freezing of the top $5-10 \mathrm{~cm}$ of water in the thickener. This ice sheet tore the ultrasonic bed depth indicator probe from the thickener as it was rotated by the motion of the rake. Outotec, working in close cooperation with Yara, was able to overcome all of these issues to enable the demonstration plant to operate smoothly and reliably.

This demonstration plant was able to provide useful and realistic operating conditions, but due to the smaller processing rate, the resultant beach slopes on the pilot-scale deposition area were significantly steeper than those which would result from full-scale discharge. Slopes of up to $13 \%$ were developed. A number of conical tailings deposits (Figures 4-7) were created during the two year period of pilot-scale operations, with the size of each cone being $200-500 \mathrm{~m}$ in diameter.

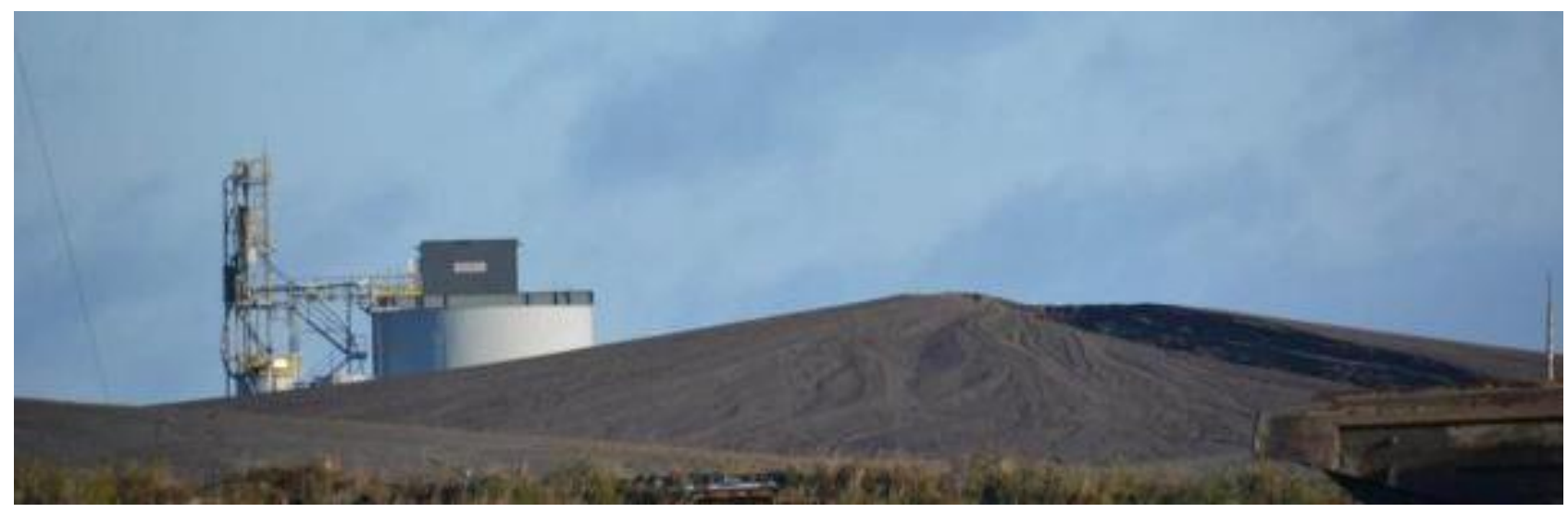

Figure 4 Conical tailings deposit that was produced by the underflow tailings from the $14 \mathrm{~m}$ diameter high-compression thickener in 2014

It was found that the beach slopes exhibited during these trials were not affected by the change of seasons. This showed that the freeze/thaw cycle had no impact on the resultant beach slopes either, which allayed any fears of slumping occurring during the summer months.

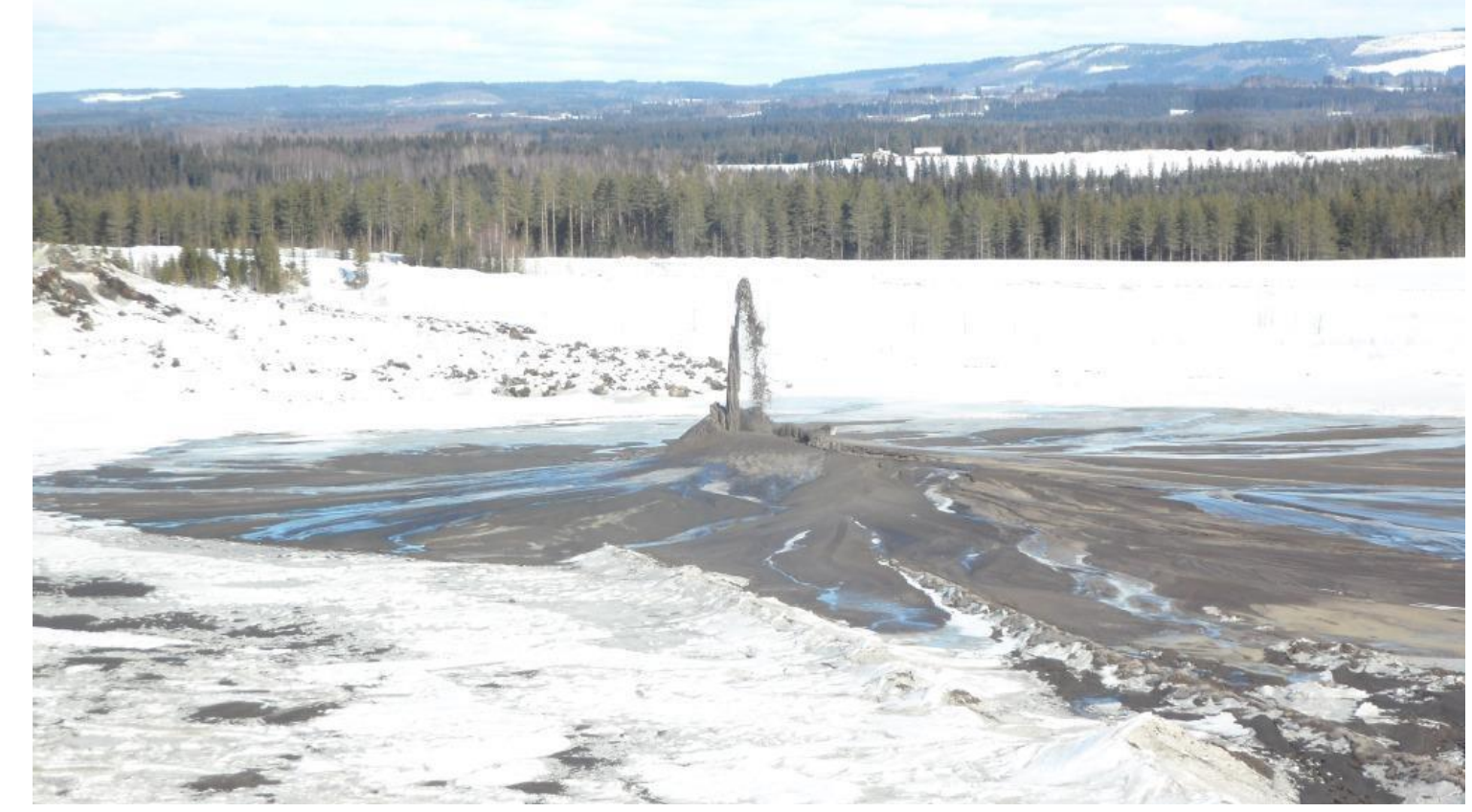

Figure 5 Tailings deposit that was produced by the underflow tailings from the $14 \mathrm{~m}$ diameter high-compression thickener in the winter of 2013 


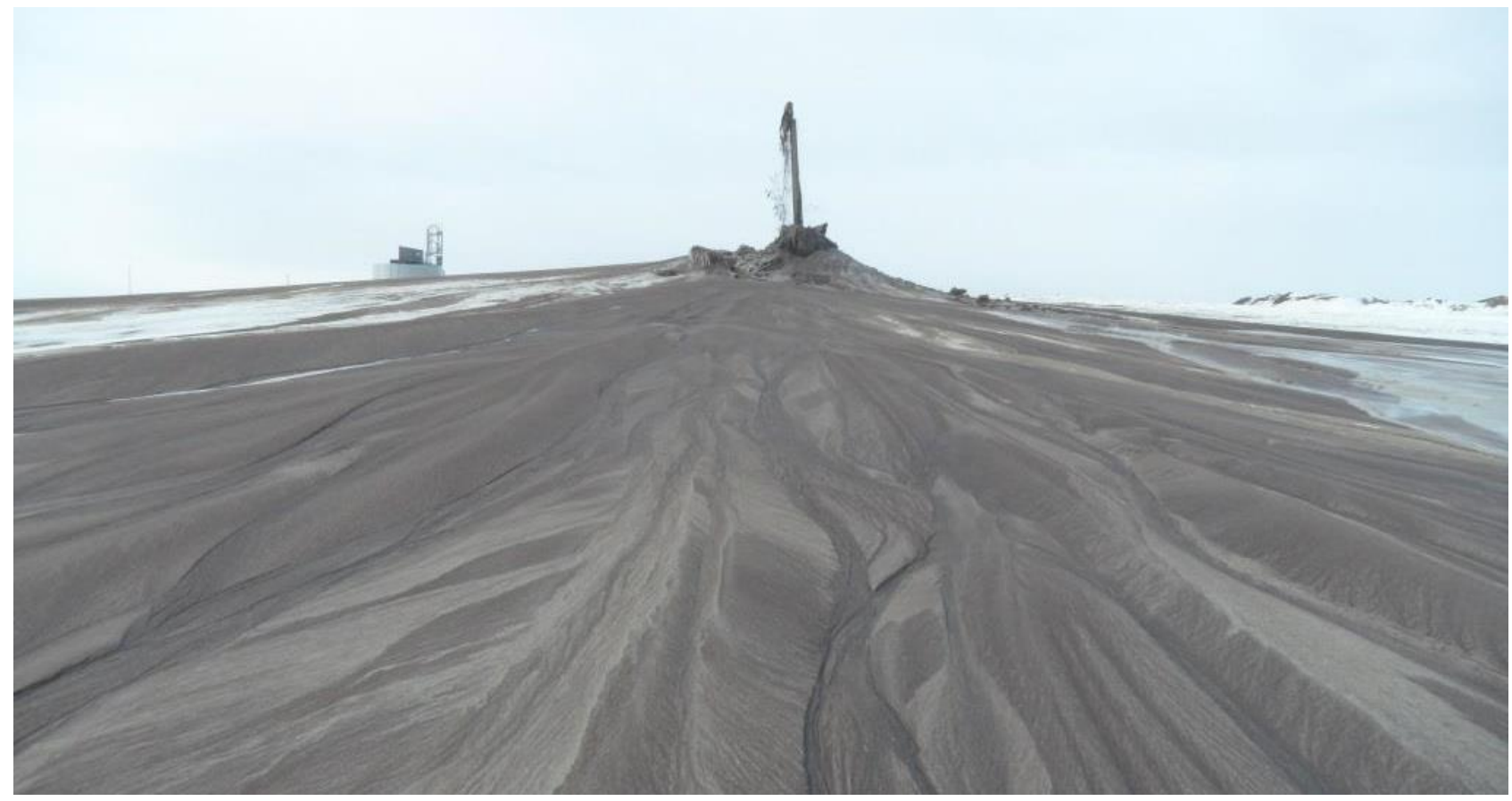

Figure 6 Tailings deposit that was produced by the underflow tailings from the $14 \mathrm{~m}$ diameter in the winter of 2013 - note the old dried up channels on the surface

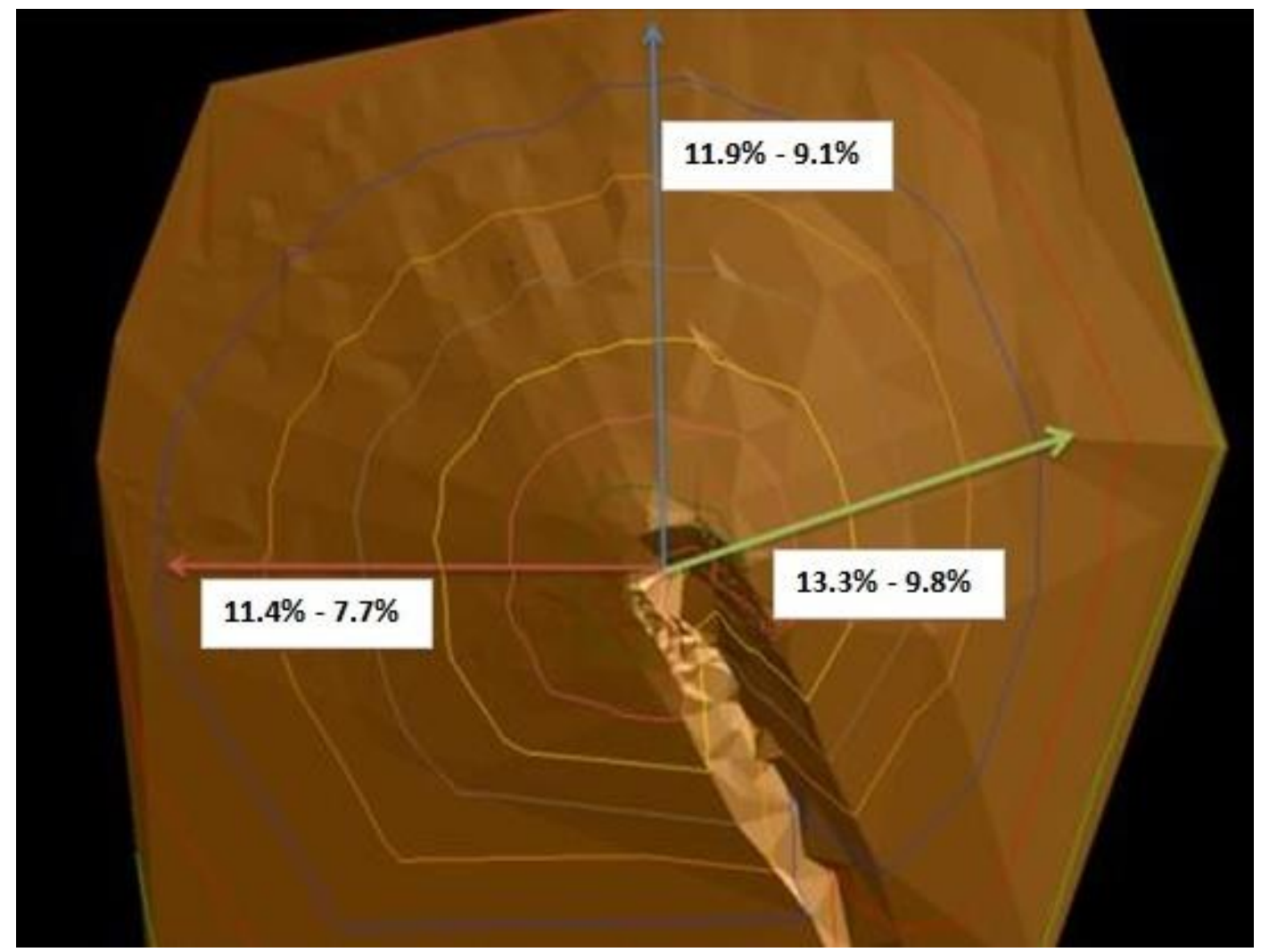

Figure 7 Image of a conical tailings deposit that was produced by the underflow tailings from the $14 \mathrm{~m}$ diameter thickener in 2014, with the range of beach slopes shown along three axes

Fitton Tailings Consultants analysed the beach slope data that was measured from these deposits in order to determine which beach slope prediction models might best apply for predicting full-scale production rates. It was found that some models provided more accurate predictions than others, so these were later used in the design of the TSF. 
Also during the operation of the demonstration plant, centrifugal and positive displacement pumps were tested, and operational data was gathered for design. As a result of the demonstration plant operation, design criteria for the full-scale thickener plant and discharge system were established that could be used for a full-scale installation.

\section{Design of the tailings storage facility}

In 2015, Yara proceeded to engage contractors to design the TSF and the necessary associated mechanical infrastructure. Fitton Tailings Consultants was contracted to develop the design for the TSF. They visited the site in 2015 to develop a design for the TSF that would exploit the beaching behaviour to the maximum economic effect, and later that year the design was completed. The proposed TSF design featured three CTD cones in order to make the most economic use of the available footprint (Figure 8 ). The beach slopes were predicted to be $6 \%\left(3.4^{\circ}\right)$ at the upper reaches of each cone, gradually flattening to a slope of $1.6 \%$ $\left(0.9^{\circ}\right)$ at the lower reaches of each cone. The predicted degree of concavity in the beach profile was calculated on the basis of the anticipated degree of variation in the slurry discharge rate and the thickener underflow concentration.

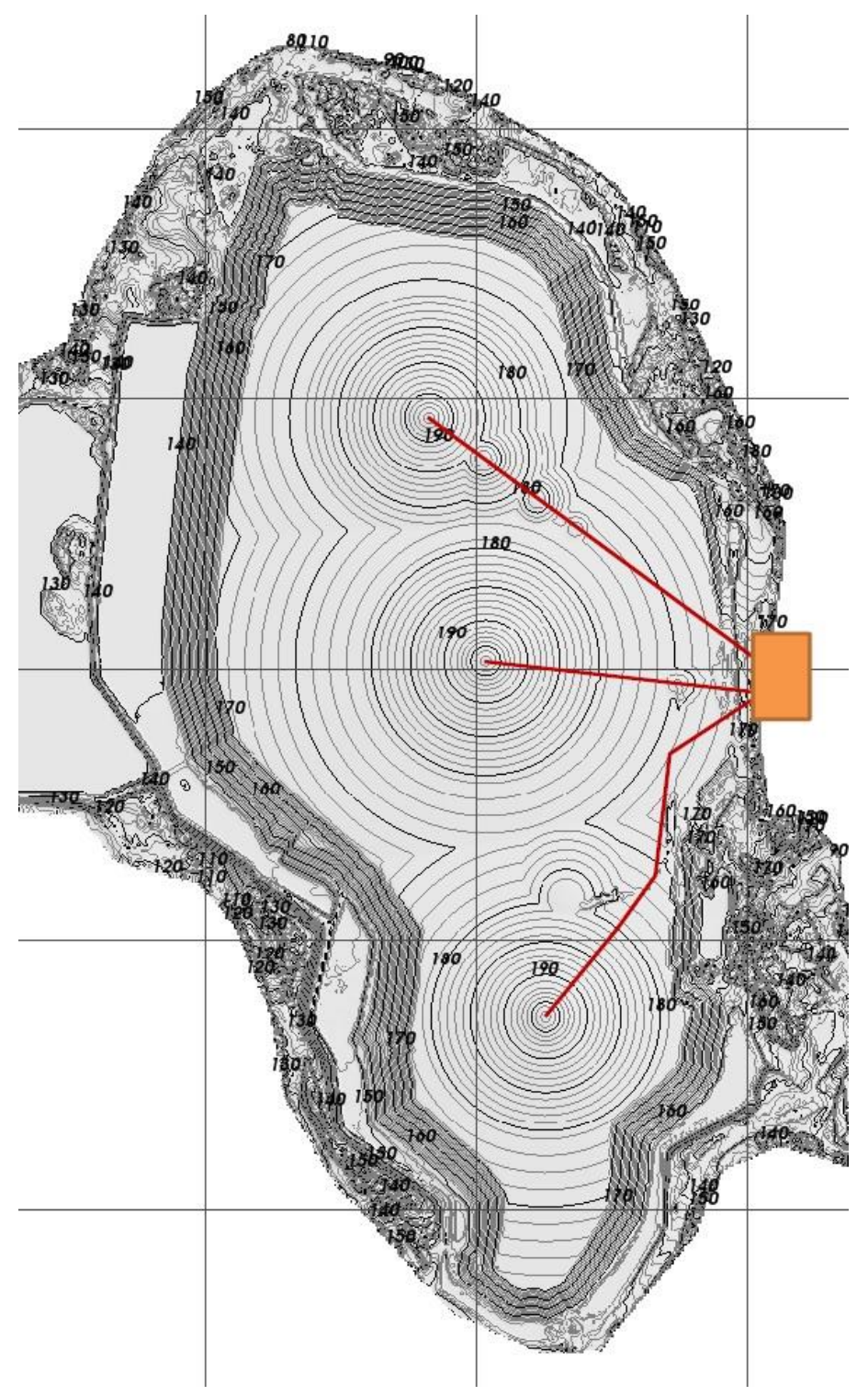

Figure 8 General layout for the Siilinjärvi TSF for the year 2032 


\section{Mechanical installation}

Also in 2015, Outotec was awarded the contract for the engineering, procurement and construction (EPC) of the paste plant, valued at over EUR $40 \mathrm{M}$. The scope of the EPC project included basic and detailed engineering, project management, procurement, construction and civil works for the foundations and buildings, installation of piping and equipment, site management, training, commissioning, start-up and the performance testing of the installation. Outotec's proprietary equipment included two $30 \mathrm{~m}$ paste thickeners (Figures 9 and 11), OKTOP slurry tank and flocculant-dosing unit. The third-party equipment and services included positive displacement pumps (Figure 10), building and piping materials, auxiliary mechanical equipment, construction and installation work.

Plant design parameters:

- Feed slurry rate $1,100 \mathrm{t} / \mathrm{hr}$ dry solids basis.

- Feed slurry flow rate $1,720 \mathrm{~m}^{3} / \mathrm{h}$ at $45-48 \% \mathrm{w} / \mathrm{w}$ solids.

- Underflow density $68-70 \% \mathrm{w} / \mathrm{w}$ solids at $940 \mathrm{~m}^{3} / \mathrm{hr}$.

- Overflow to water ponds $810 \mathrm{~m}^{3} / \mathrm{hr}$.

Thickeners:

- Thickeners $-2 \times 30 \mathrm{~m}$ diameter and total height $26 \mathrm{~m}$.

- Installed thickener rake torque 6,500,000 Nm.

Underflow discharge pumping:

- WEIR/GEHO piston diaphragm pumps.

- $2 \times$ operating and $1 \times$ standby.

- Discharge pressure up to 110 bar.

- Motor power $2.3 \mathrm{MW} /$ pump.

- Maximum flow $630 \mathrm{~m}^{3} / \mathrm{hr} /$ pump.

- Nominal flow $468 \mathrm{~m}^{3} / \mathrm{hr} /$ pump.

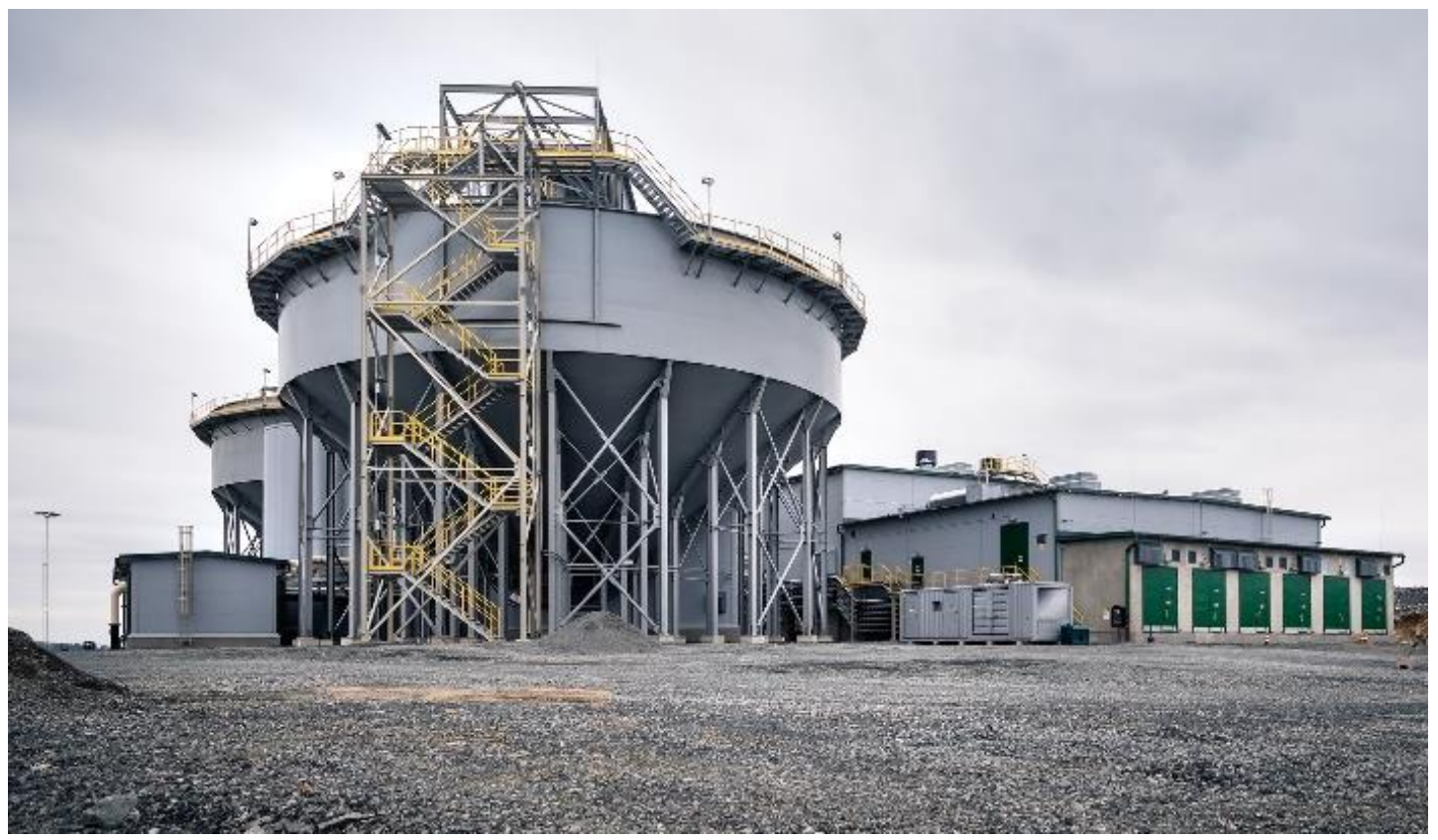

Figure 9 The two $30 \mathrm{~m}$ diameter Outotec paste thickeners installed at the Siilinjärvi Mine 


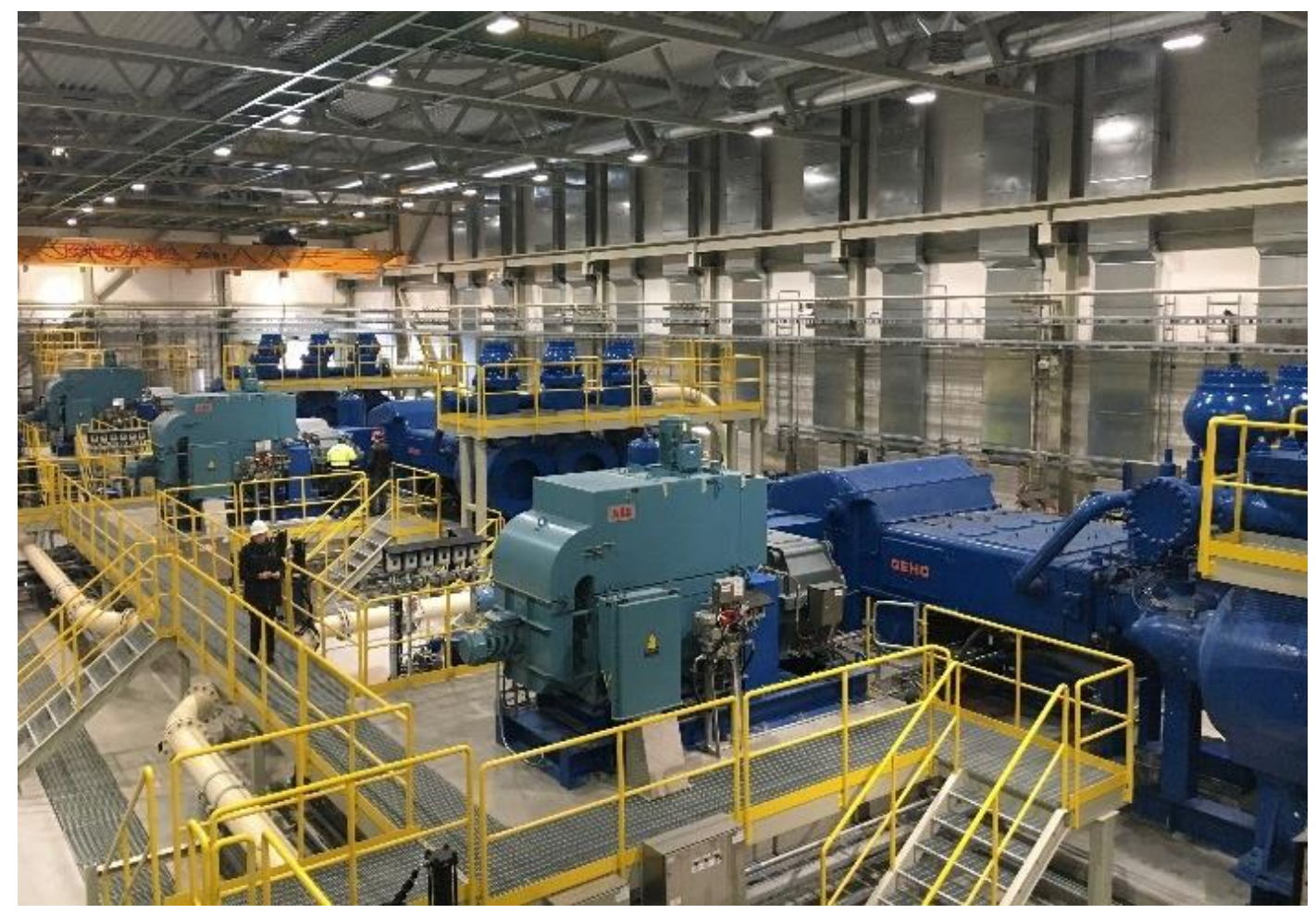

Figure 10 The three GEHO piston diaphragm positive displacement pumps installed at the Siilinjärvi Mine

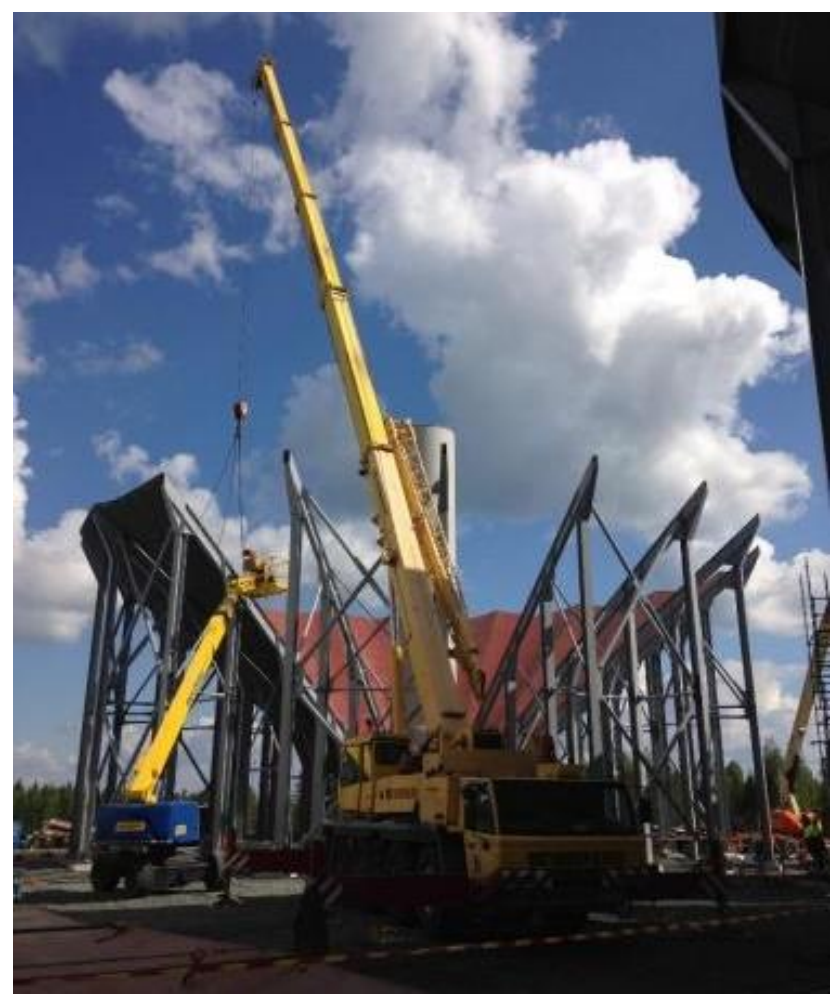

Figure 11 Construction of one of the $30 \mathrm{~m}$ thickeners - note the steep floor angle

In 2017, the paste plant with two $30 \mathrm{~m}$ paste thickeners went through water testing in freezing $-25^{\circ} \mathrm{C}$ $\left(-13^{\circ} \mathrm{F}\right)$ weather. Following slurry commissioning in February 2017, the plant passed performance testing within one month of the start-up, and the plant has been in operation ever since. 


\section{Tailings deposition}

The underflow slurry from the new thickeners has been successfully pumped to the TSF since their commissioning. The solids concentration of the underflow has averaged $67.5 \% \mathrm{w} / \mathrm{w}$ during this first nine month period, which is slightly lower than the $68 \%$ operating point that was originally anticipated. Some photos of the tailings deposition are presented in Figures 12-14.

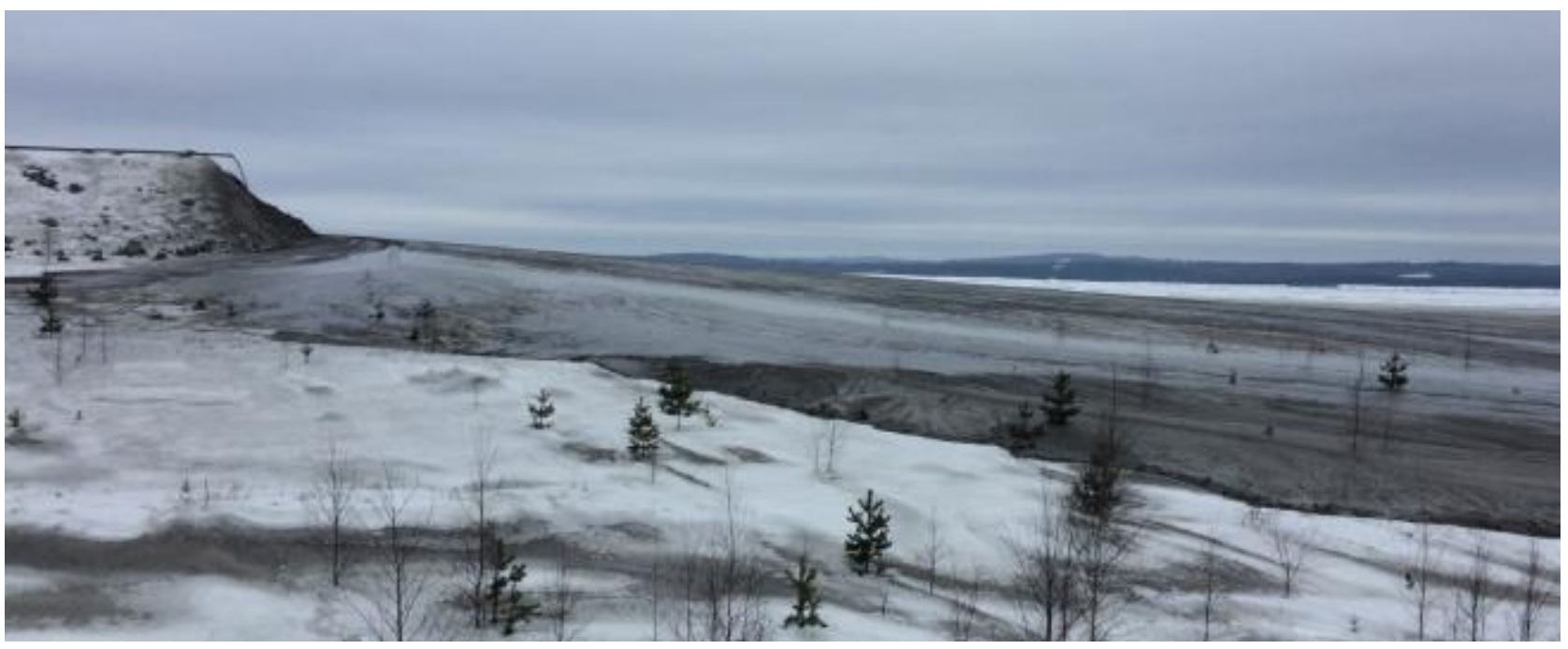

Figure 12 Tailings deposit in May 2017, after installation of the new thickened discharge system

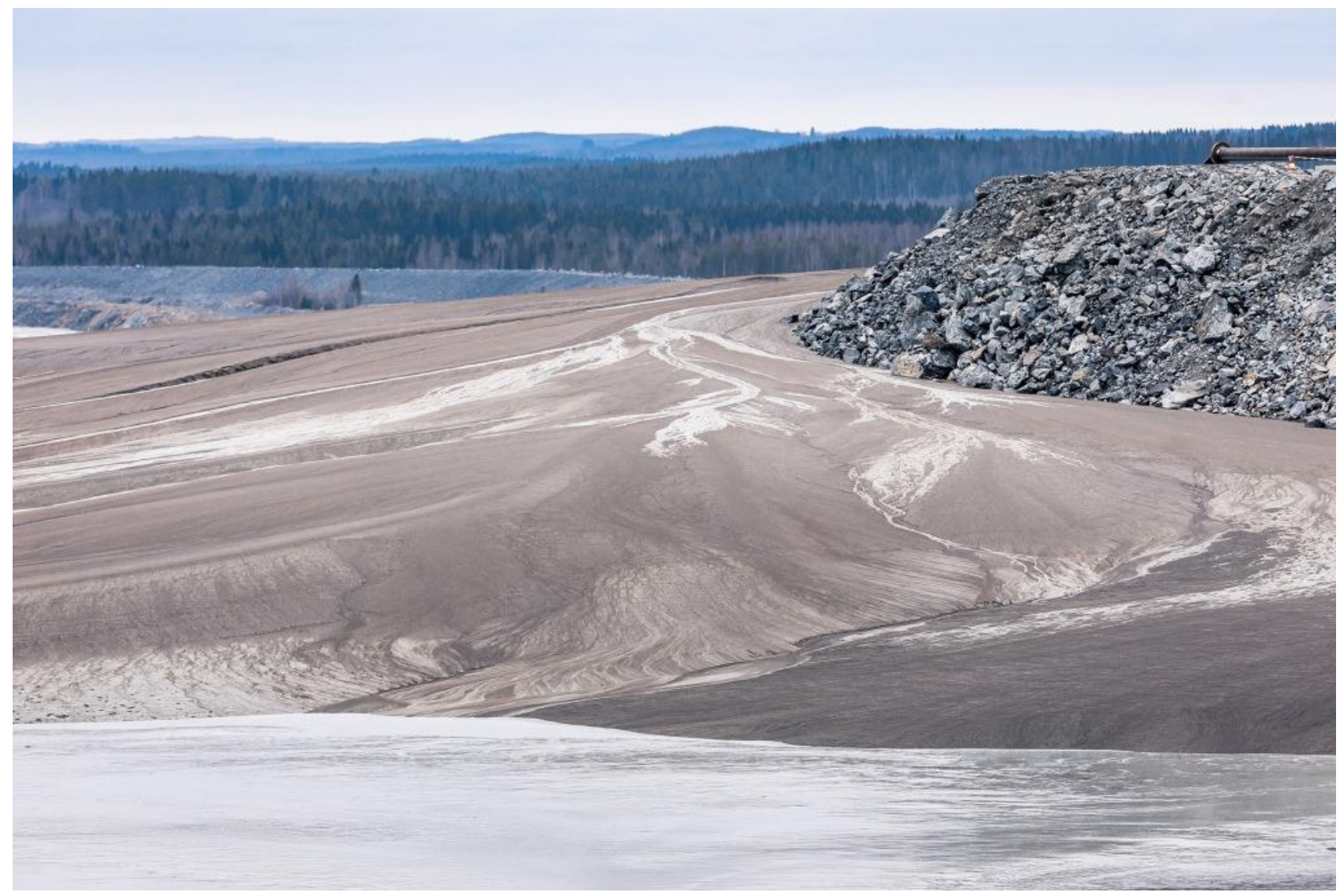

Figure 13 Tailings deposit in May 2017, with channelised flow evident 


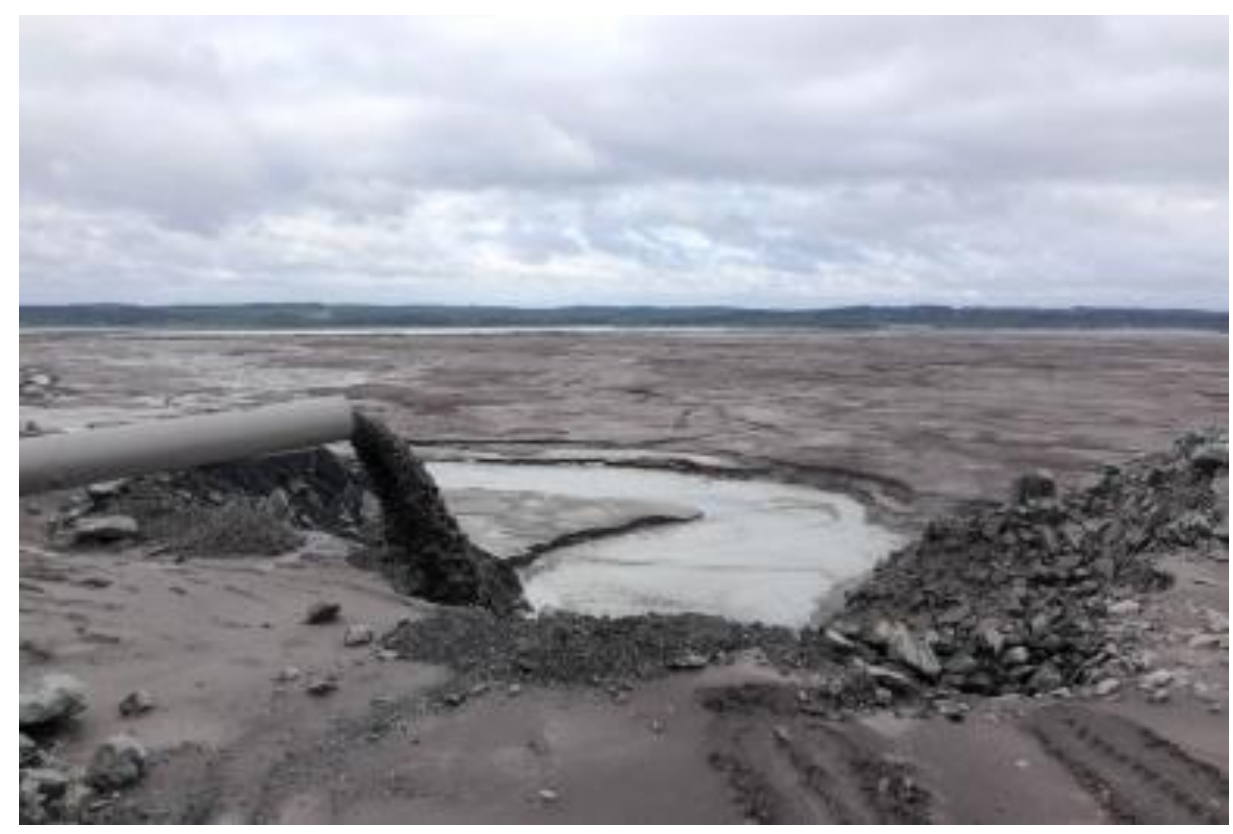

(a)

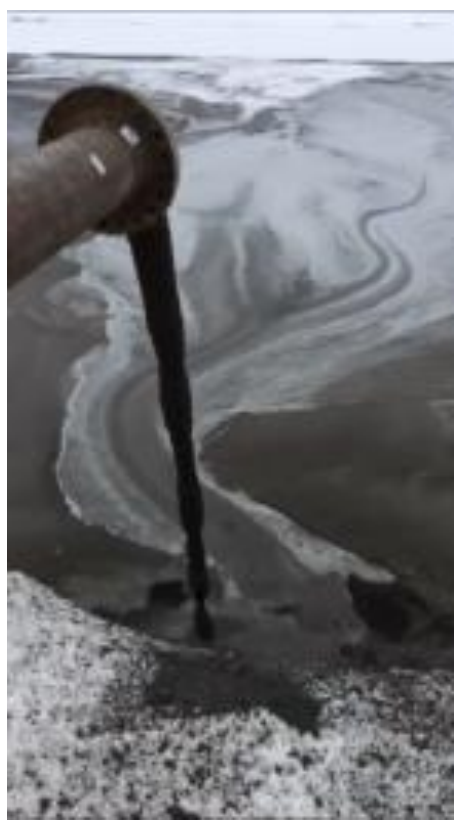

(b)

Figure 14 Tailings discharge (a) Before; and, (b) After

As of October 2017, the beach slopes are averaging 6.1\% $\left(3.5^{\circ}\right)$. This has provided strong validation for the accuracy of the predictions used in the design of the TSF, where $6.0 \%$ was adopted for the upper slopes of the three cones.

\section{Conclusion}

This paper presented a case study for a new thickened tailings installation at the Siilinjärvi mine in Finland. The climatic conditions at the site presented some engineering challenges, as did the coarse tailings particles, but each of these challenges was addressed throughout the design process. Pilot and demonstration-scale operations proved to be critical to this design process, and underlined the importance of appropriately scaled testing in this type of project to enable equipment design optimisation.

The system was commissioned in early 2017 , and has since been running successfully.

This thickened tailings installation will enable the mine to continue operating to the year 2035. In turn, this will also enable the facilities nearby to continue producing chemicals and fertiliser, with the whole complex providing 800 jobs to the local community.

\section{Acknowledgement}

The authors thank Yara International ASA for their support, and for their permission to publish this article. 